\title{
CRÍTICA LESBIANA: LECTURAS DE LA NARRATIVA ESPAÑOLA CONTEMPORÁNEA
}

\author{
MARÍA PILAR RODRÍGUEZ
}

Universidad de Deusto

Trazar un recorrido de las representaciones del lesbianismo en las distintas producciones culturales surgidas en el estado español en las últimas décadas es una tarea que se enfrenta a múltiples problemas. En primer lugar, mientras que algunos países -especialmente Estados Unidos, pero también en menor medida, Francia o Inglaterra- han visto florecer una corriente narrativa y crítica lesbiana que ha llegado a convertirse en paradigma teórico modélico para otras disciplinas, en nuestro país la carencia de estudios literarios, artísticos, históricos y sociológicos al respecto ha dificultado enormemente esta tarea. En segundo lugar, la realidad del panorama político y social actual es francamente desalentadora ya que se fundamenta en un entramado ideológico en el que las formas de expresión disidentes son generalmente proscritas. José Miguel Cortés explica nítidamente esta situación que provoca sentimientos de exclusión y de auto-marginación:

«Así, ni el modelo de relaciones de pareja o familia heterosexual, ni las prácticas sexuales (de penetración/reproducción), ni las pautas amorosas de corte romántico decimonónico, ni las representaciones culturales de propaganda heterosexista, ni las visiones religiosas de condena y ostracismo de todo lo que no vaya dirigido al matrimonio, ni las concepciones educativas de negación y ocultamiento del deseo homosexual, tienen nada que ver con nuestro mundo, con nuestra manera de entender la amistad y el amor, con nuestra forma de vivir y sentir el cuerpo. Todo ello nos ha llevado a ir creando, al margen de la mayoría, un mundo propio muy peculiar, a desarrollar una gran capacidad de disimulo, de ocultación, de temor, de mentiras y auto-odio" ${ }^{1}$.

Si tal es la situación para el componente masculino de la comunidad gay, en el caso de las mujeres todavía se ven más acrecentadas estas tendencias por

1. CORTÉS, José Miguel: «Acerca de modelos e identidades» en Vicente Aliaga y José Miguel G. Cortés. Identidad y diferencia. Sobre la cultura gay en España. Barcelona, Egales, 1997, pp. 109-198, pp. 113-114. 
la falta casi absoluta de modelos de referencia y por el marcado estigma social que la identidad lesbiana, aún hoy, conlleva². Olga Viñuales se pregunta por qué la homosexualidad femenina es menos visible y está menos institucionalizada que la masculina, y lo explica en función del carácter patriarcal de la sociedad y a la tradicional falta de recursos de las mujeres ${ }^{3}$. En el caso de la sociedad española es preciso contemplar una serie de factores políticos que han contribuido a tal invisibilidad, y que parten de la obsesiva insistencia por parte del gobierno franquista en la consagración del matrimonio y de la maternidad como las metas más preciadas a las que deberían aspirar todas las mujeres. Se ignoraron, por tanto, durante mucho tiempo, todas aquellas opciones -lesbianismo, soltería elegida, maternidad fuera de la institución matrimonial y desarrollo profesional- que de algún modo interfirieran con el modelo familiar propuesto por la legislatura, apoyado y reduplicado por el sistema educativo y por la iglesia católica $^{4}$. De este modo el lesbianismo ni siquiera se constataba como una realidad y el discurso oficial ignoró tercamente el amor y la sexualidad entre las mujeres. La herencia legislativa de tal principio ideológico se constata en las diferencias abismales existentes entre hombres y mujeres en lo referente a la homosexualidad. Antoni Mirabet i Mullol recoge el contenido de la "Ley de peligrosidad y Rehabilitación Social», cuyo texto se formuló el 4 de agosto de 1970 de la siguiente manera (Capítulo III, art. 6):

«A los que realicen actos de homosexualidad se les impondrán, para su sucesivo cumplimiento, las medidas siguientes:

a) Internamiento en un establecimiento de reeducación.

2. Como recuerda la revista Creatividad feminista-La Correa feminista: "En el estado español llevamos un cierto retraso con respecto a otros países de nuestro entorno (...) en procesos de cambio social que permitan expresiones diversas y modos de vida diferenciados. Si la lesbofobia es una práctica cotidiana a la vez que las relaciones afectivas entre personas del mismo sexo siguen constituyendo el tabú de los tabúes, no es de extrañar que haya una producción mínima de literatura lesbiana escrita por lesbianas españolas» en "Genealogías del lesbianismo: historias de mujeres y literatura» Creatividad feminista-La Correa feminista. http://www.creatividadfeminista.org/ articulos/lesb_literatura.htm, p. 6.

3. VIÑUALES, Olga: Identidades lésbicas. Discursos y prácticas. Barcelona, Bellaterra, 2000, p. 18.

4. No es el momento ahora de insistir en esta situación; me limito a mencionar el Prólogo de la Ley del 18 de julio de 1939, que declaraba: «Es consigna rigurosa de nuestra Revolución elevar y fortalecer la familia en su tradición cristiana, sociedad natural, perfecta y cimiento de la nación» (citado en SCANLON, Geraldine M.: La polémica feminista en la España contemporánea (1864-1974), Madrid, Siglo XXI, 1976, p. 320). De acuerdo con la ley, los hombres debían recibir un sueldo suficiente para poder mantener a la familia y evitar que la mujer trabajara fuera del hogar, "apartándola así de su función suprema e insustituible que es la de preparar a sus hijos, arma y base de la Nación en su doble aspecto espiritual y material» (321). Más claramente, la iglesia exponía sin ambages su mensaje por boca del padre Ruiz Amado: «La dignificación de la mujer no puede hallarse por otro camino que el del matrimonio cristiano, único, indisoluble, en el cual, junto a la subordinación que exige la unidad social, se halla la igualdad espiritual de los dos sexos» (citado en ALER GAY, Maribel: "La mujer en el discurso católico del catolicismo", Nuevas perspectivas sobre la mujer: actas de las primeras jornadas de investigación interdisciplinaria, Madrid, Seminario de Estudios de la Mujer, 1981, pp. 232-248, p. 244. 
b) Prohibición de residir en el lugar o territorio que se designe o de visitar ciertos lugares o establecimientos públicos, y sumisión a la vigilancia de delegados ${ }^{5}$ ».

Sin embargo, como reconoce el mismo estudioso, la mayoría de las legislaciones nunca mencionaban el lesbianismo. Carmen Alcalde resume la escena en la época franquista con los siguientes datos: no se tomaba en serio y nada hubiera ocurrido ante la contemplación de dos mujeres en un acto sexual; ni siquiera la policía hubiera sabido qué hacer ante una denuncia de este tipo ${ }^{6}$. Este mismo hecho es señalado por Juan Vicente Aliaga, quien al referirse a la tristemente famosa Ley de Peligrosidad y Rehabilitación Social mencionada, afirma: "Conviene puntualizar que estas leyes se aplicaban a la homosexualidad masculina. Las lesbianas, cuya sexualidad no era contemplada, fueron ignoradas en la redacción de los supuestos punibles. El silencio en torno a estas cuestiones devendrá un elemento definitorio que ha dificultado sobremanera la visibilidad lésbica»" Sólo a partir de 1975 comienzan a sucederse los actos, los manifiestos $y$ las publicaciones que confieren una identidad y un nombre a las relaciones lesbianas. Esto es un hecho importante, porque incluso más peligrosa que la persecución puede ser la negativa a reconocer una opción amorosa y sexual, ya que ello implica la ausencia total de posibles modelos para el reconocimiento y el desarrollo. En el número de octubre de 1976 de la revista Vindicación Feminista aparecía una descripción de la ideología del Frente de Liberación Homosexual del Estado Español. La reforma del 26 de diciembre de 1978 sacó a la homosexualidad del grupo de los denominados "comportamientos peligrosos». Los significados sexuales no han sido nunca fenómenos naturales ni neutrales, sino muestra palpable del conjunto de relaciones de poder cultural y social desde el que se configura la experiencia humana. Si bien en nuestra sociedad la situación dista mucho de alcanzar unas cotas mínimas de conocimiento y respeto, la posibilidad de subvertir tal estado de cosas se halla precisamente en esa arbitrariedad en cuanto a la configuración de actitudes y de prejuicios, y en la posibilidad de modificar definiciones y patrones a través del impulso social y cultural.

En el paradigma intelectual de nuestra época las identidades se entienden como fenómenos menos estables y prefijados que en épocas anteriores, y aparecen como producto de una continua negociación en la que juegan diferentes variables tales como el estatus social, la edad, el género, la nacionalidad y la raza, el nivel de instrucción y las experiencias vitales. No se entiende el lesbianismo como una identidad esencial, fija e inmutable, sino como una construcción cultural que puede ser modificada. Una misma persona puede, por lo tanto, desarrollar diversas opciones sexuales a lo largo de su vida sin que ninguna de ellas sea determinante. En los Estados Unidos, el proceso gradual de revisión metodológica que los estudios sobre la sexualidad han experimentado surge del impulso del movimiento feminista, que abrió la puerta a lo que en muchas uni-

5. MIRABET I MULLOL, Antoni: Homosexualidad hoy, Barcelona, Hender, 1985, p. 165.

6. LEVINE, Linda Gould y Gloria FEIMAN WALKMAN: Feminismo ante el franquismo. Entrevistas con feministas de España, Miami, Universal, 1980, p. 36. 
versidades se llaman hoy en día «estudios gays y lesbianos». En estos departamentos se ha desarrollado la teoría llamada queer, denominación que se apropia de una forma despectiva y peyorativa de referirse a las personas homosexuales para reivindicarla con orgullo. Rafael Mérida Jiménez afirma: «El término inglés queer designa la idea de rareza y extrañamiento pero, igualmente, a nivel coloquial, puede convertirse en un insulto sexual dirigido tanto contra hombres como contra mujeres». Los estudios queer buscan desnaturalizar conceptos tales como "género" $\mathrm{y}$ "sexualidad", atendiendo a las transformaciones sociales y culturales más que a las denominaciones esencialistas. En la década de los noventa se publica la mayoría de las aportaciones críticas y teóricas en torno al lesbianismo, pero antes de realizar un brevísimo y necesariamente incompleto repaso a las principales aportaciones teóricas de los noventa, es preciso mencionar el artículo de Adrienne Rich, titulado "Compulsory Heterosexuality and Lesbian Existence», publicado en el número 5 de la revista Signs en 1980. Se entiende la heterosexualidad como una imposición por parte de la institución patriarcal; las mujeres no eligen practicar la heterosexualidad como opción o preferencia, sino que se les impone como natural, correcta y adecuada desde una ideología tácita que actúa desde una aparente neutralidad. Otro momento importante fue la publicación en 1981 del artículo «What Has Never Been: An Overview of Lesbian Criticism»" en el que ofrecía una definición de crítica lesbiana y un panorama de las publicaciones en el campo hasta esa fecha.

En 1990 Judith Butler publicó su ya famosísimo libro Gender Trouble. Feminism and the Subversion of Identity ${ }^{10}$. Butler argumenta que la causa de la heterosexualidad obligatoria impuesta por la sociedad proviene de un orden rígido basado en una bipolarización biológica y sexual (varón y hembra), que se asocia a la dicotomía de géneros (hombre y mujer) y que se asume posteriormente como paradigma de ordenamiento de la sexualidad normativa. Busca deconstruir las nociones de género y sexo diferenciados naturalmente y subraya el carácter cultural y social de tales construcciones. En ese mismo año ve la luz la obra de Eve Kosofsky Sedwick, titulada Epistemology of the Closet ${ }^{11}$. Sugiere la necesidad de llevar a cabo una revisión del binomio "hetero/homo» y, como indica Andrés Rodrigo: «su mayor innovación radicaría en la manera en que distribuye los planos aparentemente en conflicto, pues al estrechar los vínculos entre homosociabilidad y homosexualidad desestabiliza la construcción de las identidades sexuales ${ }^{12}$. Diana Fuss

7. ALIAGA, Juan Vicente: "Cómo hemos cambiado» en ALIAGA, Juan Vicente y José Miguel G. CORTÉS: Identidad y diferencia. Sobre la cultura gay en España, pp. 17-107, p. 30.

8. MÉRIDA JIMÉNEZ, Rafael (ed.): Sexualidades transgresoras. Una antología de estudios queer, Barcelona, Icaria, 2002, p. 19.

9. ZIMMERMAN, Bonnie: "What Has Never Been: An Overview of Lesbian Feminist Criticism», Feminist Studies, 7, 3 (1981) pp. 451-475.

10. BUTLER, Judith: Gender Trouble. Feminism and the Subversión of Identity, London and New York, Routledge, 1990.

11. SEDWICK, Eve Kosofsky: Epistemology of the Closet, Berkeley, University of California, 1990.

12. RODRIGO, Andrés: «La teoría queer y el activismo social» en SEGARRA, Marta y Àngels CARABÍ, (eds.): Feminismo y crítica literaria, Barcelona, Icaria, 2000, pp. 143-158, p. 17. 
en Inside/Out: Lesbian Theories/Gay Theories ${ }^{13}$ también cuestiona esa distinción extrema entre homo y heterosexualidad y coloca la identidad lesbiana dentro y fuera a la vez de la institución normativa, más allá de la dialéctica jerárquica que da forma al binarismo. En 1990 Karla Jay y Joanne Glasgow editan Lesbian Texts and Contexts: Radical Revisions ${ }^{14}$ y en 1992 Sally Munt edita el volumen titulado New Lesbian Criticism. Literary and Cultural Readings' ${ }^{15}$. En la introducción propone la intersección de los estudios gay y lesbianos con los estudios de la mujer y con la teoría crítica, de modo que la crítica lesbiana se beneficia de las investigaciones desarrolladas en áreas tales como la teoría del discurso, la etnografía, la historiografía, la crítica literaria y el análisis audiovisual. A partir de entonces han aparecido nuevas ediciones, antologías y recopilaciones centradas en la crítica y en la narrativa lesbiana, algo que en nuestro país no ha sucedido todavía ${ }^{16}$, aunque hay que destacar esfuerzos como los realizados por Meri Torras, Olga Viñuales o Rafael Mérida Jiménez, entre otros, que ya se han mencionado aquí. Más recientemente y como estrategia subversiva para combatir nociones heredadas discriminatorias, Beatriz Preciado propone su teoría de la contra-sexualidad, una teoría del cuerpo que se sitúa fuera de las oposiciones hombre-mujer, masculino-femenino y heterosexualidad-homosexualidad y que consiste no en la lucha contra la prohibición, sino en la «producción de formas de placer-saber alternativas a la sexualidad moderna $»^{17}$. En su concepción, la heterosexualidad es una "tecnología socia ${ }^{18}{ }^{\text {» }}$ y no un origen natural fundador, y por ello resulta posible invertir y derivar sus prácticas e identidad sexual. Critica la habitual concepción de la identidad homosexual a partir de la normatividad heterosexual: "La identidad homosexual, por ejemplo, es un accidente sistemático producido por la maquinaria heterosexual y estigmatizada como anti-natural, anormal y abyecta en beneficio de la estabilidad de las prácticas de producción de lo natural ${ }^{19}$ ».

Al estudiar la producción narrativa lesbiana en el estado español, y si volvemos la vista hacia las décadas anteriores, advertimos la presencia de ciertas obras paradigmáticas que marcaron momentos decisivos tras su aparición y que todavía hoy resultan pertinentes para contextualizar en lo literario y en lo social las novelas de los noventa ${ }^{20}$. Tal vez la más conocida y la más estudiada haya

13. FUSS, Diana: Inside Out: Lesbian Theories, Gay Theories, Nueva York, Routledge, 1991.

14. JAY, Karla y Joanne GLASGOW: Lesbian Texts and Contexts. Radical Revisions, New York, New York UP, 1990.

15. MUNT, Sally: New Lesbian Criticism. Literary and Cultural Readings, New York, Columbia UP, 1992.

16. Otras dos obras teóricas de importancia son The Practice of Love: Lesbian Sexuality and Perverse Desire, de Teresa de Lauretis (Bloomington, Indiana UP, 1994) y Lesbian Studies: Settling an Agenda, de Tamsin Wilson (New York, Routledge, 1995).

17. PRECIADO, Beatriz: Manifiesto contra-sexual. Prácticas subversivas de identidad sexual, Madrid, Ópera Prima, 2002, p. 19.

18. Op. cit., p. 26.

19. Op. cit, pp. 25-26.

20. No es la intención de este breve artículo mostrar el panorama completo de la narrativa lesbiana contemporánea, tarea que aún queda por perfilar, sino tan sólo mostrar algunos de sus rasgos caracterizadores a través de las dos novelas escogidas. 
sido la novela de Esther Tusquets titulada El mismo mar de todos los veranos, publicada en 197821. Las relaciones de complicidad entre mujeres forman la base de la trama narrativa de su obra, y ésta desvela una historia de deseo y afinidad entre dos mujeres que viven entre la hipocresía y la mediocridad de la burguesía catalana. La narradora elige permanecer instalada en su matrimonio con Julio y se despide de Clara, su amante, en las últimas páginas de la novela. Su reticencia a admitir la realidad de esta relación lesbiana se hace patente en las dudas que manifiesta en el momento de nombrarla: «me sorprende constatar lo breve que ha sido mi aventura - ¿mi aventura?- con Clara, veinticinco días, veintiséis, veintisiete a lo sumo, la aventura -no puedo emplear la palabra amor, como si la vedara un secreto dolor o una oculta vergüenza- que ahora concluye en esta habitación de hote ${ }^{22}$ 》. En la página siguiente la narradora da un paso más y a la par que admite la realidad de su amor por Clara no oculta el miedo y la falta de arrojo que le impiden continuar esa relación:

"y las dos sabemos que nos queremos todavía y las dos sabemos que la situación no tiene salida (...) porque siempre, una y otra vez, yo volvería a traicionarla para traicionarme, volvería a herirla para herirme, volvería a asesinar en ella la esperanza para anular una vez más en mí toda posible esperanza, porque no existe ya para mí (...) la menor posibilidad de aprender a volar -ni ganas tengo ya de que me crezcan alas-, de seguirla más allá del estrecho marco de cualquier ventana y emprender juntas la ruta hacia las tierras de Nunca Jamás ${ }^{23}$.

Si bien el juego con los motivos de Peter Pan son recurrentes en El mismo mar de todos los veranos, no parece desacertada esa denominación territorial ( Nunca Jamás») para delimitar la situación final para las relaciones de las mujeres en la mayoría de las novelas españolas, donde por unos u otros motivos, la relación heterosexual se impone ${ }^{24}$.

En 1975 publica Carme Riera el relato corto Te deix, amor, la mar com a penyora, y resulta pertinente subrayar muy someramente algunos rasgos constitutivos de la relación lesbiana en esta narración, ya que reaparecerán en las dos novelas de los noventa aquí seleccionadas. Te deix se construye como un relato enigmático, ya que el sexo de las dos mujeres protagonistas sólo se desvela abiertamente al final del mismo. Se mantiene la ambigüedad mediante la utilización de adjetivos con terminaciones intercambiables en oposición a los de declinación masculina o femenina, y, en el original, mediante la utilización del pronombre «nosaltres», que puede referirse a dos hombres, a dos mujeres,

21. Tusquets, Esther: El mismo mar de todos los veranos, Barcelona, Lumen, 1978.

22. Op. cit., p. 226.

23. Op. cit. , pp. 227-228.

24. Es interesante constatar que muchos de los estudios críticos consagrados a esta novela se alejan de la trama lesbiana para centrarse en otros aspectos temáticos o formales de la misma. Véase, por ejemplo, SERVODIDIO, Mirella: "A Case of Pre-Oedipal and Narrativo Fixation: El mismo mar de todos los veranos, y GOULD LEVINE, Linda: «Reading, Rereading, Misreading and Rewriting the Male Canon: The NarrativeWeb of Esther Tusquets' Trilogy", en Análisis de la Literatura Española Contemporánea 12. 1-2. (1987), pp. 157-174 y 203-217. 
o a un hombre y una mujer. La construcción de ese enigma implica un mensaje social y político importante al centrarse en la precaria situación que caracteriza a las relaciones lesbianas. Este relato, de modo sutil y casi imperceptible, reflexiona sobre la presencia de la heterosexualidad obligatoria durante la época franquista y acerca de la total ausencia de modelos y referentes culturales para el lesbianismo. Al comenzar su relato, la posición de la narradora se define por su edad y por una referencia al conjunto musical de moda en la época: "Tenia quinze anys -una cançó del Dúo Dinámico, el conjunt de moda, parlava de nines tendres com flors i tu, per fer-me enrabiar, la cantaves ${ }^{25}$ ». Esa mención trivial a una canción nos sitúa en unas coordinadas históricas y sociales en las que el desarrollo femenino a partir de la adolescencia no tiene cabida fuera del modelo paradigmático obligatorio del amor entre un hombre y una mujer (todas las canciones del Dúo Dinámico y todas las canciones de la época hablaban de este único tipo posible de enamoramiento). Al estatus marginal o prohibido de esa relación que comienza a desarrollarse corresponden unos espacios apartados, alejados de las miradas; escondidos. Los primeros encuentros se producen en el concierto del Teatro Nuevo, a través de miradas encontradas en la oscuridad, que se privilegia sobre la luz del escenario iluminado. La oscuridad se articula como único espacio posible para el desarrollo del amor lesbiano, condenado a no ser sino espectáculo privado, episodio oculto creado a espaldas de la iluminación y de lo público. De la vista se pasa al tacto: los primeros besos y los primeros abrazos se describen en el espacio de las excursiones al campo. Es en este momento cuando afirma la narradora: "Anava descobrint el món de la mateixa manera que l'amor em descobria a mi per fer-me seva. No era als llibres, ni a les pellícules on aprenia a viure, aprenia a morir de mica en mica -però això no ho sabia aleshores-, quan, abraçada a tu, em negaba a deixar passar el temps» ${ }^{26}$.

El aprendizaje del mundo y el aprendizaje del amor se funden en esta cita en la que además hay una alusión a la ausencia cultural de representación del lesbianismo en la literatura y en el cine. Como ha señalado Bonnie Zimmerman: "Heterosexist societies render lesbians invisible and unspeakable» ${ }^{27}$, y tal era el caso en la sociedad española entonces, donde como ha señalado la propia Riera, la palabra "lesbiana» ni siquiera estaba incluida en los diccionarios al uso ${ }^{28}$. Frente a la carencia de modelos culturales donde

25. Te deix, amor, la mar com a penyora, Barcelona, Laia, 1975, p.16. "Tenía quince años-una canción del Dúo Dinámico,el conjunto musical de moda, hablaba de tiernas muchachas en flor, y tú me la cantabas para hacerme rabiar», Te dejo el mar, Madrid, Espasa-Calpe, 1991. Trad. Luisa Cotoner, p. 54.

26. Op. cit., p. 18: «Iba descubriendo el mundo al mismo tiempo que el amor iba descubriéndome a mí para hacerme suya. No fue en los libros ni en las películas donde aprendí a vivir la historia de nuestra historia. Aprendía a vivir, aprendía a morir poco a poco -aunque entonces no lo supiera-, cuando abrazada a ti, me negaba a que el tiempo se me escapase» (56).

27. "Las sociedades heterosexistas vuelven a las lesbianas invisibles e innombrables» ("Lesbians Like This and That: Some Notes on Lesbian Criticism for the Nineties» en MUNT, Sally (ed.): New Lesbian Criticism. Literary and Cultural Readings, New York, Columbia UP, 1992, pp. 1-15, p. 9.

28. Recogido en NICHOLS, Geraldine: Escribir, espacio propio: Laforet, Matute, Moix, Tusquets, Riera y Roig por sí mismas, Minneapolis, Ideologies and Literatures, 1989. 
reconocerse ${ }^{29}$, la propia experiencia y el cuerpo de la amada se convierten en las sendas disponibles para el aprendizaje, y a su vez, este relato se convierte en uno de los primeros en la literatura española en los que una futura joven podrá aprender a leer «la historia de su historia».

El encuentro sexual entre las mujeres se produce en un barco, en un espacio alejado nuevamente del centro, y se articula como reflejo especular de los dos cuerpos femeninos. El lenguaje muestra una forma de conocimiento sexual que no reduplica la representación habitual del erotismo fálico, y esta forma innovadora de retratar los encuentros sexuales entre mujeres se advertirá igualmente en las dos novelas de los noventa, como veremos. A partir de ese momento, tal vez lo más revelador para entender el desarrollo de la historia sea precisamente aquello que queda velado o sólo parcialmente desvelado: las prohibiciones, las alusiones al escándalo público, los "comentaris a mitja veu ${ }^{30}$ », y la amenaza del padre: «Aquest és el camí de la depravació. T'enviaré a Barcelona, si això dura un dia més ${ }^{31}{ }$. La construcción discursiva de la identidad lesbiana está oficialmente ausente y nadie se atreve a darle nombre tampoco en el terreno más cercano y familiar.

El final de la novela se aparta de la posibilidad de continuación de ese amor lesbiano (que nunca desaparece como tal) y se decanta por la opción matrimonial para la narradora. Los prejuicios de la sociedad heterosexista retratada se dejan entrever en comentarios y amenazas, e incluso en la aparente aceptación por parte de Toni, el futuro esposo de la joven, que no deja de ser problemática: "Li semblà una història bella i malatissa. Tu li caigueres bé, et trobà intelligent, amable, malgrat que el teu aspecto hi veié qualque cosa rara, inquietant, obscurament perillosa ${ }^{32}$ 》. Tras las impresiones del novio se trasluce la amenaza que siente ante dos males tradicionalmente atribuidos al lesbianismo: la enfermedad, propia de las explicaciones psicoanalíticas habituales de la homosexualidad, y el peligro que rechaza la sociedad patriarcal ante lo que entiende como un alejamiento de la mujer de sus funciones habituales de madre y esposa. Como afirma Adrienne Rich en "Compulsory Heterosexuality and Lesbian Existente», cualquier afirmación que trata la experiencia lesbiana como marginal, menos normal, o como imagen especular de una relación heterosexual, queda seriamente debilitada ${ }^{33}$. En este punto de cierre la narradora anuncia su embarazo

29. Fefa Vila, activista lesbiana, afirma: «Desde el punto de vista de las lesbianas, existe una carencia tal de un referente simbólico, que para reconocernos es imprescindible que existan cada vez más y más modelos (...) Creo que es necesario que proliferen modelos diversos", en "Voces y ecos de la comunidad gay en España» en ALIAGA, Vicente y José Miguel G. CORTES: Identidad y diferencia. Sobre la cultura gay en España, pp. 201-235, p. 228.

30. Op.cit., p. 19. "comentarios a media voz» (57).

31. Op. cit. p. 19. «Éste es el camino de la depravación. Te mandaré a Barcelona si esto dura un día más» (57).

32. Op. cit., p. 31. "Le pareció que se trataba de una historia enfermiza y bella. Tú le caíste bien, te encontró inteligente, amable, a pesar de que, en tu aspecto, percibió algo raro, inquietante, oscuramente peligroso» (68).

33. RICH, Adrienne: "Compulsory Heterosexuality and Lesbian Existence», en Blood, Bread and Poetry: Selected Prose: 1979-1985, New York, Norton, 1986, p. 120. 
y lo que ella considera su muerte próxima. Es aquí también donde por primera vez en el relato se produce el alumbramiento de la relación lesbiana como tal, al desvelar el nombre que piensa imponer a su hija: "Pense que probablement no coneixeré la nina, perquè serà nina, n'estic segura, i no podré decidir, si no ho faig ara, el seu nom. Vull que li posin el teu, Maria, i vull també, que llencin el meu cos a la mar, que no l'enterrin ${ }^{34}{ }^{\prime}$. Los efectos deletéreos del abandono obligatorio del amor lesbiano parecen conducir a la destrucción y a la muerte, y de este modo la historia insiste en la necesidad de un desarrollo amoroso personal elegido en un contexto de tolerancia y de aceptación desafortunadamente ausente en la sociedad de ese momento.

Las novelas de la década de los noventa que aquí se analizan proponen una serie de continuidades con las pautas indicadas anteriormente, a la par que sugieren profundas transformaciones. Tal vez el rasgo más innovador sea que por fin el lesbianismo se atreve a decir su nombre: se abandonan las reticencias y las ambigüedades y las relaciones amorosas y sexuales entre las mujeres ocupan el centro de la narración, y a ellas se dedica el núcleo argumental. Efectos secundarios y Tu nombre escrito en el agua sugieren dos modos muy distintos de entender estas relaciones, y para comprender mejor estas dos vertientes resulta útil acudir a la teoría expuesta por Eva Legido-Quiley ${ }^{35}$ para la novela erótica española escrita por mujeres. Distingue entre una poética erótica que tiende hacia Eros «si la obra manifiesta una actitud vitalista, que se puede dar tanto en un sentido de celebración de los deleites del placer erótico y sus derivados, como en un afán de resolución de situaciones conflictivas que obstaculizan la afirmación de la vida ${ }^{36}{ }_{»}$. En este tipo de narrativa, la relación sexual se describe desde una perspectiva entusiasta y enaltecedora, en la que la ternura del sentimiento se une al vigor de la pasión sexual. Por último, una característica fundamental en esta poética erótica que tiende hacia Eros es la capacidad del amor para actuar como forma de conocimiento. En contraposición, en palabras de Legido-Quigley, «una obra se aproxima a Thanatos si se desprende una postura antivitalista que se puede referir tanto a un regodeo en diferentes manifestaciones que se acercan a la muerte, como a una posición implícita de no luchar frente a lo que frena la vida ${ }^{37}$ ». En tales obras se llega a advertir incluso una celebración de lo irracional de la muerte y de la destrucción en la que se anulan las posibilidades de disfrute y de amor. Se niega el alcance del conocimiento, y en ocasiones se busca lograr el choque y el impacto incluso desde una perspectiva tremendista y decadentista: «El modo de hacerlo ya no es aumentando el grado de la experiencia erótica (porque su valor como tabú se ha desgastado), sino a través

34. Op. cit., p. 32. "Creo que probablemente no conoceré a la niña -porque será una niña, estoy segura-y no podré decidir su nombre si no lo hago ahora. Quiero que le pongan el tuyo, María, y quiero también que echen mi cuerpo al mar, que no lo entierren» (68).

35. LEGIDO-QUIGLEY, Eva: ¿Qué viva Eros? De la subversión posfranquista al thanatismo posmoderno en la narrativa erótica de escritoras españolas contemporáneas, Madrid, Talasa, 1999.

36. Op. cit., p. 16.

37. Op. cit., p. 16. 
de la thanática, asociando el sexo con la muerte y convirtiendo el mundo en un antimundo; esto es, eliminando los contenidos éticos de la faz de la tierra ${ }^{38}$ ».

Tu nombre escrito en el agua ${ }^{39}$, de la autora que firma bajo el pseudónimo de Irene González Frei, ganó el premio La Sonrisa Vertical de 1995 y su mayor mérito tal vez resida, como se indica en Creatividad feminista, en ser una de las primeras escritas en lengua castellana abiertamente "lesbiana». En efecto, la obra consiste en el monólogo que Sofía, la protagonista, dirige a Marina, su amante, entrelazado con el recuerdo de su vida sexual antes y después de conocerla. Las relaciones sexuales de Sofía con los hombres antes de conocer a Marina, y en especial con Santiago, su marido, están marcadas en todo momento por la frustración y la insatisfacción, y progresivamente por el dolor, la crueldad y la mutua destrucción. Si al comienzo del matrimonio la masturbación y la contemplación en el espejo son las fuentes de consecución del placer que no logra obtener de la penetración, más adelante la relación entre Sofía y Santiago se desarrolla en escenas violentas, sadomasoquistas y degradantes para ambos, que tampoco le procuran satisfacción. El punto culminante en esa espiral de violencia se produce cuando la protagonista sufre un aborto al ser brutalmente penetrada por Santiago con un tubo de plástico de dimensiones desmesuradas. La narradora descarga su conciencia al distribuir a partes iguales las responsabilidades:

"La conciencia me exige confesar que mi sed de erotismo de entonces prefería beber de ese tumultuoso manantial que irrigamos juntos desde nuestro primer acto sexual, violento y cargado de rivalidad (...). Por ello exijo que no se impute a Santiago por lo menos esa parte de mis desgracias. Ambos fuimos verdugos y ambos fuimos víctimas de nuestra relación enferma» ${ }^{40}$.

Tras el conocimiento de la mujer que transformará decisivamente la vida de Sofía, la relación lesbiana con Marina y en su descripción por medio de un lenguaje poético y sensual permitirá a la novela mostrar su mayor radicalidad innovadora. La expresión se desarrolla por medio del mito de Narciso en una acepción que va más allá de la admiración del propio reflejo, y que se centra en la figura del doble ${ }^{41}$. Como señala Ivonne Cuadra: "La dualidad de estos personajes femeninos conforman la expresión de un deseo sexual igual ${ }^{42}$. Al extraordinario parecido físico entre las dos mujeres se superpone un equilibrio

38. Op. cit., p. 39.

39. GONZÁLEZ FREI, Irene: Tu nombre escrito en el agua, Barcelona, Tusquets, 1995.

40. Op. cit., p. 84.

41. Hay numerosísimas citas en la novela que insisten en esta noción; por ejemplo: «(...) y éramos dos figuras gemelas, multiplicadas por miles en las paredes, irrepetibles, iguales, gozando en cada uno de los reflejos y de las figuras» (218), o «(..) y el orgasmo nos llegó a la vez, un mismo orgasmo que sobrevino simultáneamente en dos personas gemelas, lento y perfecto, como los dos afluentes del mismo río, las dos puntas iguales de un solo nudo, las dos caras inseparables de una única moneda, como un hueso roto que acaba por soldarse» (171).

42. CUADRA, Ivonne: «Tu nombre escrito en el agua: hacia una nueva representación del sujeto homoerótico", Espéculo 16 (2003), pp. 1-9, p. 5. 
en lo amoroso y en lo sexual, mediante el cual ambas funcionan igualmente como sujetos y como objetos de deseo, en una relación en la que la ternura sustituye a la violencia anterior. La comunión profunda que se alcanza en el encuentro de los cuerpos ya se adivina en la descripción de su primer abrazo en la piscina: "Volví a ver el amor de dos cuerpos idénticos que llegan a la vez a un único orgasmo, abrazados y sumergidos en el agua de dos bocas reunidas en el único beso verdaderamente amante» ${ }^{43}$.

El lenguaje, que ha servido a la narradora para describir sus anteriores relaciones con los hombres, no parece ahora suficiente para expresar la intensidad del sentimiento amoroso y sexual lesbiano, y por ello se crean nuevas fórmulas expresivas basadas en la fusión y en la alternancia pronominal. Bonnie Zimmerman ha definido este tipo de prácticas textuales lesbianas del siguiente modo:

«Lesbian textual practices create a narrative space in which writer and reader, or writer and assumed audience, or female characters, come together in a relationship defined as lesbian (...). As Marilyn Farwell explains: "Confusing the boundaries between subject/object and lover/beloved undercuts the heterosexuality which is based on this dualism». In general, lesbian critical reading proposes the blurring of boundaries between self and other, subject and object, lover and beloved, as the lesbian moment in any text» ${ }^{44}$.

La diferencia en la intensidad del placer alcanzado en la interacción sexual se marca en expresiones que insisten en la radical novedad de esta nueva experiencia con otro cuerpo femenino: «el orgasmo era largo, era inagotable, se perpetuaba como nunca, me elevaba hasta el punto máximo del deleite, donde yo jamás había llegado", pero esos momentos lesbianos de fusión que describe Zimmerman, caracterizados por la indeterminación entre las fronteras personales, se plasman con claridad en fragmentos como éste:

«Marina, Marina nuestra, me amamos, te amaste más que nunca, soñamos que te veías y yo eras Clara, porque ella multipliqué nuestros sueños y te besamos mi coño, lo recorriste con la punta de mi lengua y puse tus dedos junto a nuestros labios que ardíais, te abriste mi abismo, giramos, volviste a penetrarte, con la sonrisa desgarrada de la felicidad, Marina, te corrimos en mí, me fuimos, tú me amamos, Sofía, para siempre» ${ }^{45}$.

Clara es el nombre dado a un espacio nuevo creado para simbolizar la unión entre ambas mujeres, la fusión, la unión y la expresión máxima del deseo feme-

43. Op. cit., p. 121.

44. "Las prácticas textuales crean un espacio narrativo en el que la escritora y la lectora, o la escritora y su supuesta audiencia, o los personajes femeninos, se hacen una en una relación que se define como lesbiana (...) Como explica Marilyn Farwell: "La confusión de los límites entre sujeto/objeto y amante/amada socava la heterosexualidad, que se basa en tales dualismos». En general, la lectura crítica lesbiana propone la indeterminación de los límites entre el ser y el/la otro/a, sujeto y objeto, amante y amada, como el momento lesbiano del texto". ZIMMERMAN, Bonnie: "Lesbians Like This and That: Some Notes on Lesbian Criticism for the Nineties» en Sally MUNT: New Lesbian Criticism, pp. 1-15, p. 10-11.

45. Op. cit., p. 213. 
nino. En esa consciente confusión de formas pronominales y verbales se logra la indeterminación entre sujeto y objeto, amante y amada, y se hace posible la expresión de una sexualidad lesbiana que no se somete al lenguaje patriarcal.

Otro aspecto relevante de la novela reside en la formulación del lesbianismo como fenómeno social. Dando voz a la idea formulada por Adrienne Rich y anteriormente mencionada, distingue entre el carácter supuestamente natural de la heterosexualidad frente al esfuerzo de voluntad necesario para asumir la relación lesbiana: "El amor heterosexual es, desde esta perspectiva y sólo desde ella, más fácil: sobreviene de un modo casi natural y no exige una agobiante gestación de la propia voluntad ${ }^{46}$. Se percibe, además, una abierta constatación de los prejuicios propios y ajenos que surgen ante la nueva condición de amar a una mujer. "Amar a una mujer me convertiría en alguien diferente, en la posible víctima de una desaprobación generalizada, aun en nuestros tiempos supuestamente más tolerantes ${ }^{47}$ ». La narradora asiste a una fiesta en la que todas las participantes son mujeres y debe confrontar su propia resistencia a verse incluida en tal grupo, a insertarse en una comunidad lesbiana. La extensa cita siguiente define a la perfección este sentimiento primero de inseguridad que con el tiempo da paso al cuestionamiento de la supuesta normalidad de las relaciones heterosexuales:

«La única respuesta que he encontrado por ahora es que adolezco de cierta testarudez, de cierta ceguera, de cierta vergüenza, o como quiera llamarse, con respecto a mi homosexualidad. Yo siempre había creído ser normal, todo lo normal que puede ser cualquier persona, y la presencia de esas mujeres me revelaba a gritos mi verdadera naturaleza, me arrojaba en una categoría a la que yo nunca había sospechado pertenecer, me calificaba con un epíteto que hasta ese día yo hubiera rechazado. Con el tiempo, comprendería que la llamada normalidad no es más que una cuestión de estadística, pero allí, en la fiesta, me parecía ver en Marina el espejo perfecto de mi propio deseo y mi propio ser, y en cambio, en las otras, el espejo deformado de mi escandalosa anormalidad» ${ }^{48}$.

Este tipo de reflexiones, si bien pueden parecer algo ingenuas en ciertos momentos, resultan sin embargo útiles en un panorama narrativo en el que la carencia de un discurso lesbiano autorreflexivo es tan flagrante. Estos logros, sin embargo, se ven ciertamente menguados por un final de la novela en el que predominan el absoluto dominio y la brutalidad masculina que destruyen los momentos narrativos lesbianos que se habían construido. El relato en sí mismo se enmarca entre dos narraciones de un mismo hecho, pero contado de muy diferente modo: mientras que la primera versión parece no ser sino un episodio pornográfico más al uso entre un hombre y dos mujeres, el epílogo desvela que se trataba de un ataque y de la doble violación por parte de Santiago hacia Sofía y Marina que culmina con el asesinato de esta última. Cabe interpretar este

46. Op. cit., p. 188

47. Op. cit. p., 149

48. Op. cit., pp. 186-7. 
peculiar acercamiento a los sucesos como un crítica a la brutalidad masculina que en los relatos oficiales queda habitualmente suavizada o manipulada en el terreno erótico, convirtiendo una violación o un asesinato en una posible experiencia consentida. Sin embargo, ese final de destrucción, de violencia y de muerte se agudiza con la decisión última de Sofía de autoinmolarse como único medio de reunión con su amante, en otra imagen truculenta en la que la protagonista descubre que su nuevo amante, el travesti Baxi tiene SIDA, y decide morder su pene infectado para así alcanzar la unión y la fusión definitiva con Marina.

El catálogo de horrores que se va desplegando en esta última parte de la novela impide la consecución de un espacio lesbiano fuera del terreno idealizado de la breve experiencia erótica y amorosa en el que se instalan las protagonistas: "Nuestro amor fue como un sueño, un juego de espejos, un resplandor en las sombras y ya no existe ${ }^{49}$. Siguiendo la tendencia thanática apuntada por Legido-Quigley hacia la destrucción, la muerte se configura como el único espacio posible, y ello perpetúa una cartografía vital plagada de tristezas y lamentaciones, en la que las mujeres lesbianas son víctimas sin posibilidades de redención. Para Sofía, tras la muerte de Marina no hay avance en el conocimiento, y tras varios intentos fallidos de conocer el pasado de Marina a través de un recorrido por los lugares donde aquélla vivió, no puede sino entregarse a la muerte. Los momentos de placer y de gozo correspondientes a la relación entre las mujeres descritos anteriormente quedan de este modo borrados por este final trágico y por la progresiva desaparición de ambas protagonistas, que se acentúa en la cita final: "Y en el epitafio de nuestros sepulcros habrá un solo nombre, el mismo, que desaparecerá cuando tú y yo al fin nos reencontremos, Marina, porque todos los nombres se inscriben en el agua, en la corriente que pasa y no regresa ${ }^{50}$.

Muy otro es el panorama que presenta Efectos secundarios ${ }^{51}$, novela que se aleja de la versión thanática para aproximarse definitivamente a una experiencia vital más cercana a Eros, ligada al gozo sexual y al conocimiento vital. La obra de Etxenike contribuye a crear nuevos espacios posibles para la experiencia del amor entre mujeres y a la vez crea nuevas fórmulas para la expresión del placer. Como sugiere Nicole Brossard: "A lesbian who does not reinvent the word/world is a lesbian in the process of disappearing» ${ }^{52}$.

49. Op. cit. , p. 288.

50. Op. cit., p. 288. Al leer los sucesivos episodios de crueldad excesiva y hasta de extravagancia en cuanto a la crueldad física con la que Santiago se ensaña al atacar los cuerpos de las mujeres, vienen a la mente las reflexiones formuladas por Legido-Quigley al referirse a ciertas producciones eróticas contemporáneas: "Hoy en día se trata de ver a quién se le ocurre la mayor crueldad, el placer más escabroso o la mayor barrabasada. Tal vez lo que se echa de menos es un retrato más verosímil de las relaciones eróticas, a un nivel más cotidiano, en un plano más común, de una vida menos excéntrica y apocalíptica» (39).

51. ETXENIKE, Luisa: Efectos secundarios, Vitoria, Bassarai, 1996.

52. "Una lesbiana que no reinventa la palabra / el mundo es una lesbiana en proceso de desaparición». Citado por Zimmerman: «Lesbians Like This and That», p. 10. 
La imagen del cuerpo adquiere una relevancia fundamental en el desarrollo de la historia, y se convierte en lugar de concentración de transformaciones físicas, psíquicas y emocionales. La novela se abre con la articulación del placer del cuerpo, ligado este placer a la pasión por la escritura, a la pulsión por encontrar las palabras justas que sirvan para capturarlo y para recrearlo. Así se describe el gozo que proporciona el primer encuentro con el cuerpo de la amada:

"Yo acaricio su cuerpo. Sus pechos pequeños, su vientre liso y quieto, sus muslos duros, tan calientes; su pubis ancho. Y la nombro como en otro principio.

La primera vez dije:

-Quítate la ropa.

Y luego dije:

-Tu vello espeso. Tus clavículas mínimas. Tus pezones oscuros.

Porque el deseo era sobre todo decirla.

(...)

Yo voy acariciando su piel más suave y la pronuncio. Y añado: "quiero tu placer, dámelo, abundante, dámelo»" ${ }^{53}$.

La inscripción textual del cuerpo adquiere tonos cercanos a la creación original y resuena con los ecos bíblicos de la palabra que deviene cuerpo. En esas palabras se fusionan la contemplación, el deseo erótico y la formulación del cuerpo anatómico y del cuerpo textual, construidos a través del movimiento y de la alternancia de voces y de fragmentos. Sin embargo, la expresión del cuerpo erótico y del placer pronto adquiere connotaciones de conflicto y de sufrimiento a causa de la enfermedad la aparición del cáncer de pecho en Maritxu, una de las protagonistas. Las reacciones que el descubrimiento y el tratamiento de la enfermedad provocan en ella y en su amante, Laura, atraviesan varias etapas: Maritxu siente la vulnerabilidad de ver su cuerpo disminuido y mutilado, siente la abyección de su "cuerpo repulsivo, indeseable»" ${ }^{54}$, y teme que Laura la abandone. Pero en este caso, a través de las interacciones entre ambas, se produce un proceso de aceptación del cuerpo y de la herida y se descubre una nueva dignidad corporal. Laura pasa del miedo a perder a su amante a la constatación de su amor lesbiano y al abandono de su marido, Joaquín. Laura siente que ha cruzado una frontera al admitir: «Vergüenza por haberme callado y callado y callado " ${ }^{55}$. Es más, al experimentar una época difícil de convivencia con el marido tras la confesión de su amor por Maritxu, Laura la define como días de "gestos copiados", y los soporta "porque me permiten conservar la esperanza de que al final de tantos y tantos días de incomprensión y de abandono, habrá una puerta. Y del otro lado, el camino de regreso a La cordura ${ }^{56}$. Así es, en efecto; tras experimentar vacilaciones en la relación amorosa y altibajos en los vaivenes del deseo, las mujeres deciden finalmente vivir juntas, sin idealismos exacerbados, tras haber alcanzado un mayor conocimiento de sí mismas.

53. Op. cit., p. 15.

54. Op. cit., p. 105.

55. Op. cit., p. 52.

56. Op. cit., p. 92. 
El texto evita el ocultamiento y propone una apertura y una visibilidad mayor para el amor de las mujeres. Afirma Laura: «-Hemos vivido encerradas, ocultas. $\mathrm{Mi}$ amor por ti sólo era verdad cuando estábamos solas. ¿¿No es eso una especie de mentira?». La respuesta de Maritxu a esta nueva situación expresada por su amante es la siguiente: «-El mundo va a parecerme mucho más hermoso, multiplicado ${ }^{57}$, y parece posible aventurar que también el panorama de la narrativa contemporánea se va abriendo hacia opciones más reales y más vitales de exploración del amor para las mujeres ${ }^{58}$.

No ha sido éste más que un somero repaso al panorama crítico y narrativo de escritura lesbiana contemporánea. El camino está abierto y cabe esperar la llegada de nuevas aportaciones que amplíen la visión social y cultural de una experiencia que no debe quedar oculta o relegada a espacios virtuales de la vida de nuestro país. La escritura y la distribución de estas novelas contribuye a crear modelos de referencia, harto necesarios en un panorama donde tanto han escaseado. Es deseable que la felicidad que el texto de Luisa Etxenike augura para sus protagonistas sea una realidad para el futuro de las mujeres ficticias y reales que eligen esta opción amorosa.

57. Op. cit., p. 100.

58. Para un análisis más detallado de esta novela, véase mi artículo titulado «El (re)conocimiento del cuerpo y el placer del lenguaje: Efectos secundarios» en Vidas im/propias. Transformaciones del sujeto femenino en la narrativa española contemporánea, Indiana, Purdue, 2000, pp. 166-177. 